\title{
A FILOSOFIA DE ARISTÓTELES: CONTRIBUIÇÕES PARA A FORMAÇÃO DE PROFESSORES NA EDUCAÇÃO CONTEMPORÂNEA
}

\author{
Mateus de Freitas Barreiro, Alonso Bezerra de Carvalho \\ Universidade Estadual Paulista - UNESP, ${ }^{1}$ Programa de Pós-Graduação em Educação, Marília, SP. CNPq - Conselho \\ Nacional de Desenvolvimento Científico e Tecnológico. Email: mateusfbb@bol.com.br
}

\begin{abstract}
RESUMO
Este artigo tem por objetivo trazer as contribuições sobre a ética aristotélica para a Educação Contemporânea. Na pesquisa será investigado o conceito de amizade na filosofia de Aristóteles, a fim de compreender as relações professor-aluno na sala de aula contemporânea. As reflexões trazidas por filósofos sobre o tema ética e amizade, especialmente por Aristóteles, contribuem significativamente para a compreensão das relações na sala de aula contemporânea, para agregar pressupostos éticos, tendo em vista a relação professor-aluno. Por fim, ao repensar a formação ética que Aristóteles atribui à função do cidadão na Pólis, através da elucidação da amizade, serão levantadas questões que se remeterão à formação de professores e alunos dentro de uma perspectiva que trabalhe a dimensão ética em conjunto com a dimensão epistêmica - preparando o sujeito para o trabalho e para o exercício da cidadania.

Palavras- chave: Aristóteles, ética e educação.
\end{abstract}

\section{PHILOSOPHY OF ARISTÓTELES: CONTRIBUTIONS TO FOR TEACHER FORMATION IN CONTEMPORARY EDUCATION}

\begin{abstract}
This paper aims to bring the contributions on Aristotelian ethics for Contemporary Education. In the research will investigate the concept of friendship in Aristóteles's philosophy in order to understand the teacher-student relationships in the contemporary classroom. The reflections brought about by philosophers to ethical theme and friendship, especially by Aristóteles, contribute significantly to the understanding of the relationships in the contemporary classroom to aggregate ethical assumptions, in view of the teacher-student relationship. Finally, to rethink the ethics training that Aristóteles assigns the function of the citizen in Polis, through the elucidation of friendship, issues that forward to the shaping of teachers and students within a perspective that works the ethical dimension together with the dimension will be raised epistemic- preparing the subject for work and citizenship.
\end{abstract}

Key words: Aristóteles, ethics and education. 


\section{INTRODUÇÃO}

A incorporação e a disseminação de pressupostos éticos perpassam por quaisquer atividades relacionadas à formação, pedagogia e organização da sociedade. Retomar uma ética aristotélica da amizade na sala de aula contemporânea nos inspira a repensar sobre a formação continuada dos professores e a preocupação em formar-se e formar o aluno cidadão.

A educação caminhou sempre próxima da filosofia desde a Antiguidade, pois a filosofia se constituiu com uma intenção educacional de formar o ser humano. Já a cultura contemporânea, é influenciada pela forma científica de fundamentar o conhecimento. Por mais importante que seja a ciência para a construção da educação, ela não pode descartar, na nossa visão, a análise de um viés filosófico para o entendimento de conceitos como os de amizade, virtude e o contexto social contemporâneo, visando inclusive auxiliar a educação a trabalhar a própria contribuição científica. Portanto, ao aproximar a antiguidade e a atualidade, é preciso ter como orientação alguns pressupostos citados por Cambi (1991), que auxiliaram a nortear a pesquisa: submeter os problemas de hoje a uma indagação científica do passado, restituindo o passado nas suas diferenças com o presente; aprender a relativizar ideias e ampliar as possibilidades pedagógicas dos educadores, tendo em vista que a educação não é um "destino", mas uma construção social que se renova. (CAMBI, 1999, p.13).

Para que a reflexão sobre uma "ética aristotélica da amizade" se torne uma práxis, é fundamental que na formação dos professores, seja de fato, desenvolvida a capacidade de refletir sobre sua própria prática na sala de aula para formar professores e alunos dentro de uma perspectiva que trabalhe a dimensão ética em conjunto com a dimensão epistêmica - preparando o sujeito para o mercado de trabalho e ao mesmo tempo para o exercício de sua cidadania. Portanto, a ética não se limita apenas a um sistema conceitual filosófico sobre como se orientar com base nas regras ou a perpetuação de valores morais, mas antes de tudo, a ética é o hábito que constitui o sujeito para orientar ações visando o bem dos demais cidadãos.

O objetivo deste estudo é o de elucidar o conceito de amizade aristotélico, para levantar questões que se remeterão à formação de professores e alunos dentro de uma perspectiva que trabalhe a dimensão ética em conjunto com a dimensão epistêmica - preparando o sujeito para o trabalho e para o exercício da cidadania.

\section{METODOLOGIA}

Trata-se de uma pesquisa de caráter essencialmente teórico-filosófica na área de Filosofia da Educação que será desenvolvida por meio da análise, clarificação, compreensão, 
aprofundamento, contextualização e exposição de conceitos, restabelecimento de movimentos argumentativos, identificação de teses e explicitação de pressupostos. O método específico desta pesquisa compreende a leitura, fichamento, interpretação e produção de textos que ajudem na compreensão do problema a ser tratado.

Embora a filosofia da educação tenha um caráter epistemológico, ao levantar questões sobre o processo de produção, sistematização do conhecimento presente no caráter praxiológico da educação, é preciso considerar que a educação é também de natureza prática, não se deixando reduzir como se fosse um simples objeto, pois pressupõe mediações subjetivas de todos aqueles que estão envolvidos com ela. (SEVERINO, 1990, p.22-23). Portanto, a filosofia se relaciona com a educação através de uma complementariedade nos termos conceituais postulados por Aristóteles.

\section{RESULTADOS}

É evidente que se discutirmos a relação entre professor-aluno na atualidade, sem delimitar as diferenças advindas deste vínculo, haverá uma incongruência de ordem epistemológica e pedagógica. Embora haja esta diferença entre o professor-aluno, este encontro é constituído em um espaço comum - a sala de aula, que pode ser um lugar não apenas voltado para a aprendizagem de conteúdos técnicos, mas um lugar onde também é possível se relacionar com outro eticamente, contribuindo para a formação de um sujeito com senso de justiça e responsabilidade perante a sociedade. É de suma importância que os professores não restrinjam a sua prática pedagógica em verdades cristalizadas para o aluno memorizar, como se não houvesse uma história de vida e uma realidade social entrelaçada, o que poderia ser o ponto de partida para a construção e interlocução com o conhecimento construído a partir de um diálogo que vise criar subsídios para formar um cidadão virtuoso, inserido nas discussões éticas e políticas como preconizava Aristóteles.

\section{DISCUSSÃO}

A amizade é uma temática que foi destacada por diversos filósofos da antiguidade ${ }^{1}$, mas a importância de estudar Aristóteles, além de subsidiar as discussões contemporâneas sobre o tema, reside em sua primazia: foi o primeiro tratado sistematizado sobre ética, que abrange o agir humano e as relações entre os indivíduos, o que destaca sua importância na história da filosofia. Já na Renascença, o interesse pelo tema amizade aos poucos foi se perdendo, por parte dos

\footnotetext{
${ }^{1}$ Platão dedicou a esse tema um diálogo inteiro sobre a amizade em (Lísis); Aristóteles postulou suas reflexões principalmente em dois livros (oitavo e nono) da Ética Nicomaquéia, e depois deles, Epicuro, Sêneca e Cícero (BALDINI, 2000, p.10-11).
} 
filósofos ${ }^{2}$. Atualmente o tema da amizade, vem sendo retomado por psicanalistas, educadores, sociólogos e outros pensadores que visam compreender os meandros das relações humanas em diferentes contextos institucionais.

No livro "Amizade \& Filósofos", Baldini (2000) organizou uma coletânea de textos de autores que postulam diferentes concepções sobre o conceito de amizade. Nesta coletânea, o conceito de amizade para Aristóteles é descrito como uma virtude e categorizada em três tipos: em amizades acidentais que são aquelas passageiras, e ocorrem principalmente entre as pessoas idosas (que procuram utilidade), entre jovens (que procuram o prazer) e a amizade perfeita que é diferente por ocorrer entre os "homens de bem" e os "semelhantes na virtude" (BALDINI, 2000, p.14). Além da coletânea de Baldini sobre os principais pensadores da amizade, há o livro "Genealogias da Amizade" de Ortega, que segundo o autor não é um livro essencialmente filosófico, que pretende analisar a amizade de Platão à Montaigne, procurando também focalizar uma perspectiva genealógica, para contextualizá-los e introduzi-los em uma reflexão maior (ORTEGA, 2002, p.12).

No âmbito da relação entre filosofia e educação sobre o tema da amizade, foi também estudado por Selles com o título: "La educación de la amistad: una aproximación conceptual" que relaciona o conceito de amizade entre os principais pensadores da História da Filosofia e sua relação com a Educação (SELLES, 2008).

Os comentadores ${ }^{3}$ do campo da filosofia são fundamentais para a compreensão dos conceitos de Aristóteles na formulação de uma problemática interligada com o campo da educação. Dentro da área da Filosofia da Educação, há alguns autores que trazem Aristóteles para o campo da educação através de temas variados, no entanto, a bibliografia ainda é escassa ${ }^{4}$. Mais escassa ainda quando o tema é delimitado ao conceito de Amizade aristotélica e a área da educação ${ }^{5}$

\footnotetext{
2 "Bacon, por exemplo, trata disso apressadamente, dedicando-lhe umas poucas páginas em seus célebres Ensaios e Kant faz o mesmo em suas Lições de Ética. Schopenhauer, Nietzsche e Croce também escrevem sobre a amizade, mas apenas, pode-se dizer, com a mão esquerda" (BALDINI, 2000, p.11).

${ }^{3}$ Embora muitos comentadores da obra de Aristóteles discorram sobre o conceito de amizade na forma de capítulos ou em algumas passagens, podemos destacar o livro "Amizade em Aristóteles" (MORAES,1999) por ser dedicado exclusivamente a estudar a teoria da amizade aristotélica, dividindo o texto em duas partes fundamentais, na primeira o texto em português e a segunda em grego.

${ }^{4}$ Hourdakis escreveu o livro "Aristóteles e a Educação" dedicando a inserção do pensamento de Aristóteles no campo da educação a partir da ética e política. Nas referências Bibliográficas, Hourdakis dedica uma parte de Estudos de Aristóteles e a Educação citando autores de diversos países (HOURDAKIS, 2001). Além das bibliografias citadas por Hourdakis, podemos citar o livro de Cenci, na versão traduzida tem o título de "Aristóteles \& a Educação" (CENCl,2012). Já Schmied-Kowarzik inseriu Aristóteles dentro da pedagogia dialética vinculada aos estudos de Paulo Freire (SCHMIED, 1983).

No artigo La educación como ideal de Estado: reflexiones en torno al livro VIII de la Política de Aristóteles, Muñoz discute a política e a função do cidadão na pólis grega, e ao inserir Aristóteles no campo educacional para refletir problemas contemporâneos que apontam para um caminho de interesses individuais e particulares voltados ao mercado (MUÑOZ, 2013).

${ }^{5}$ Carvalho e Colombani dedicaram pesquisas relacionando amizade de Aristóteles com o conceito contemporâneo de sala aula (CARVALHO e COLOMBANI, 2010b).
} 
Em Ética a Nicômaco, Aristóteles destaca a importância do vínculo entre as pessoas, para que através da amizade fosse possível formar um cidadão ético e participante da comunidade política com disposição de caráter para o conhecimento. Aristóteles sustenta que "a amizade ajuda os jovens a evitar o erro; ajuda os mais velhos, amparando-os em suas necessidades e suprindo as atividades que estimulam a prática de nobres ações, pois com amigos - "dois que andam juntos" - as pessoas são mais capazes de agir e de pensar" (ARISTÓTELES, 2012, p.163). Contudo, é fundamental refletir sobre os caminhos que Aristóteles teria proposto ao descrever as disposições emocionais que perpassam a amizade, e como construir caminhos fundamentados no pensando deste filósofo grego, que possa contribuir para trabalhar as dissonâncias entre professor-aluno na sala de aula.

Aristóteles (e também outros filósofos gregos da antiguidade) dizia que para formar o indivíduo era necessário resgatar bem o sentido da Paideia grega, ou seja, para ele, a formação dos indivíduos não se deveria restringir a um processo de transmissão de conteúdos, mas os agentes do processo deveriam participar dos argumentos racionais, e também se alimentar dos impulsos passionais (CARVALHO, 2010, p.3). Ao estreitar as relações pessoais dentro da escola, tendo em vista à ética, é possível favorecer aprendizagem e o ensino de aspectos racionais e emocionais, bem como buscar caminhos através dos gestos, escuta e da fala ao trabalhar os conflitos dentro e fora da escola.

O estudo de Aristóteles nos leva a retomar a amizade na sala de aula, visando contribuir para com a formação cidadã do aluno, através da conciliação entre as esferas racionais e emocionais na relação professor-aluno, ou seja, a virtude (aretê) que é encontrada no meio termo (mesótês) entre o excesso e a falta, e é divisível em virtudes intelectuais e virtudes morais.

Neste sentido, o que a filosofia de Aristóteles poderá nos ensinar para repensar a sala de aula nos dias de hoje?

O estudo de Aristóteles é pertinente e atual quando se vê na sociedade e nas escolas problemas como violência escolar, sentimentos de rivalidade entre professor-aluno e resistência dos alunos para se envolver com questões referentes ao aprendizado de conteúdos que muitas vezes não tem uma relação com o cotidiano. A proposta de estudar a amizade para Aristóteles vem ao encontro dessas questões atuais citadas acima, o que nos leva a pensar sobre a importância do professor-cidadão em incorporar preceitos éticos visando aprimorar sua prática dentro e fora das escolas. 
Aristóteles preconizou vincular o ensino associando ética e política à formação moral e à participação do cidadão na Polis, visando integrar os conteúdos racionais e a formação ética ${ }^{6}$ do cidadão, a partir da virtude intelectual e moral: a primeira é proveniente do ensino, a segunda é resultado do hábito, sendo que tais virtudes não são inatas, mas emanam através do hábito.

De acordo com Carvalho a relação entre professor e aluno, sob a óptica da sala de aula, utilizando o tema amizade como elemento provocador de reflexão, pode colaborar na elaboração de saídas significativas para a violência e conflitos dentro da escola, favorecendo inclusive, um modo alternativo sobre o saber que ali circula. (CARVALHO, 2010, p.12). Atualmente a sociedade está passando por um processo de perda de sentido moral na educação e em outras áreas. Daí a importância do elo de amizade constituído entre professor-aluno, elo este permeado por emoções/paixões de alteridade extremamente importante para pré-dispor o aluno a uma condição mais favorável à aprendizagem moral e intelectual, e também transpor essas práticas nas suas relações com o outro. Em contrapartida, o comprometimento do vínculo entre professor, acaba gerando sentimentos de inimizade permeados por emoções/paixões que geram efeitos negativos para formação da virtude moral e virtude intelectual dos alunos na sociedade e sala de aula.

Além da possibilidade de reforçar a formação ética na sala para o bem comum em sociedade e conciliar o logos (razão e linguagem) com emoções e inclinações, podendo trabalhar a dimensão ética para produzir e se apropriar socialmente do conhecimento científico na sala de aula, seria, um ensino refletido da ciência para problematizar a sua importância e o seu uso. Não há, portanto oposição entre ética e ciência e sim, complementariedade. A interdisciplinaridade e a contextualização social do conhecimento são caminhos que atualmente são utilizadas por alguns professores na sala de aula.

\section{CONCLUSÃO}

As questões discutidas até então referentes à amizade e sua possível relação com o vínculo professor-aluno nos dias de hoje e seus efeitos, nos remete à concepção que Aristóteles tinha da educação, isto é, como uma a tarefa de formar o cidadão para habituá-lo a discernir os aspectos relevantes das circunstâncias particulares, para escolher qual a melhor atitude a ser tomada em determinada circunstância. Em suma, pode-se dizer que formar um cidadão virtuoso fora e dentro da escola, consiste em habituá-lo às circunstâncias concretas, a partir de modelos do bom e

\footnotetext{
8 "A ética, como parte da filosofia, é considerada por Aristóteles uma ciência prática - cujo resultado não é exterior ao agente - que, na ordem prática, está situada na dependência da política (cf. Cidade) (PELLEGRIN, 2010, p.28). 
melhor que estão acima de sua individualidade. O bom vínculo entre professor-aluno facilitará o ensino e possibilitará formar pessoas éticas dentro e fora da escola para contribuir com uma sociedade que nos dias atuais vem se distanciando de sentimentos como a ética, o respeito ao próximo e às relações de empatia em prol de interesses individuais.

\section{REFERÊNCIAS}

ARISTÓTELES. Ética a Nicômaco. Trad. Torrieri Guimarães. São Paulo: Editora Martin Claret, 2012a.

BALDINI, M. Amizade \& Filósofos. Trad. Antônio Angonese e Laureano Pelegrini. Bauru: Editora do Sagrado Coração, 2000b.

CAMBI, Franco. História da pedagogia. São Paulo: UNESP, 1999.

CARVALHO, A. B. Alteridade e amizade na educação: A sala de aula como um espaço ético. In: $V$ Congresso Internacional de Filosofia e Educação, 2010. ANAIS DO V CINFE - Congresso Internacional de Filosofia e Educação. Caxias do Sul: Universidade de Caxias do Sul, Caxias do Sul, 2010.

CARVALHO, A. B.; COLOMBANI, F. Filosofia e educação: amizade na sala de aula. Unesp. PróReitoria de Graduação. (org.) Caderno de Formação: Formação de professores: educação, cultura e desenvolvimento. São Paulo: Cultura Acadêmica, v.2, p. 60-73, 2010.

CENCl, A. V. Aristóteles \& a Educação. Belo Horizonte: Autêntica, ed1, 2012.

HOURDAKIS, A. Aristótoles e a Educação. Trad. Luiz Paulo Rounet. São Paulo: Edições Loyola, 2001.

MORAES, J. J. A amizade em Aristóteles. Londrina: Uel, 1999.

MUÑOZ, Yepes; ALEXIS, Wilfer. La educación como ideal de Estado: reflexiones en torno al libro VIII de la Política de Aristóteles. Revista Lasallista de Investigación, v. 10, n. 2, 2014.

ORTEGA, F. Genealogias da amizade. São Paulo: lluminuras Ltda, 2002.

PELLEGRIN, P. Vocabulário de Aristóteles. Trad. Claúdia Berliner. São Paulo: Martins Fontes, 2010.

SCHMIED-KOWARZIK, W. Pedagogia dialética: de Aristóteles a Paulo Freire. São Paulo: Brasiliense, 1983.

SEVERINO, Antônio Joaquim. A contribuição da filosofia para a educação Brasília, Aberto, ano 9, n.45,p.19-25, jan./mar.1990.

SELLÉS, J. F. La educación de la amistad: una aproximación conceptual. Educación Y Educadores. v. 11, n. 1, 2008. 